\title{
A NOVEL REGIONAL ECOLOGICAL ASSESSMENT TECHNOLOGY BASED ON IMPROVED ELECTRE METHOD
}

\author{
YU, J.-P.* - YU, W.-Y. \\ School of Economics and Management, Yanshan University, Qinhuangdao 066004, PR China \\ Research Center of Regional Economic Development of Yanshan University, Qinhuangdao \\ 066004, PR China \\ *Corresponding author \\ e-mail: 3398849494@qq.com
}

(Received 27 $7^{\text {th }}$ Sep 2018; accepted $16^{\text {th }}$ Jul 2019)

\begin{abstract}
A lot of efforts have been made in ecological assessment and applications. At present, Chinese government attaches great importance to regional economic development, so this research takes China as the research object. For this reason, a novel regional ecological assessment technology is proposed based on improved ELECTRE method. In the improved ELECTRE method, concordance index, nonconcordance index, credibility index, consistent credibility, non-consistent credibility and net credibility are defined firstly, and the preference matrix, the relation of group individuals is also defined. Based on these definitions, it can be sorted for the quality of all alternatives according to the net credibility. Experimental results suggest that the proposed improved ELECTRE method is feasible and valid to the regional ecological assessment.
\end{abstract}

Keywords: concordance index, non-concordance index, credibility index, consistent credibility, nonconsistent credibility, net credibility, relation of group individuals, sort of group decision

\section{Introduction}

In the eastern coastal areas and western areas to be developed in China, massive forest lands and wetlands have been damaged, leading to a situation of combined environmental pollution and massive ecological degradation (Anbari, 2003; Bi et al., 2015; Zuo et al., 2015). By ecological assessment, the key area for ecological environmental protection and restoration can be determined, ecological function zoning can be carried out, and proper protective measures and development plans can be made for different areas, to provide a scientific reference for determining urban development scale, land use arrangement and urban system configuration (Heilmann, 2013).

So far, a lot of efforts have been made in ecological assessment and application domestically and overseas (Nichols and Wahlen, 2004; Yang, 2015). The research contents include selection and analysis of sensitivity indexes of ecological environment, assessment of ecosystem service function and value, ecological risk analysis and prewarning. The research range covers ecological sensitivity analysis under the context of global climate change, analysis of regional or watershed ecosystem dynamic change and difference, and provincial and municipal ecosystem assessment and ecological functional zoning (Zou et al., 2015; Zhao, 2003; Changdar et al., 2015; Lin and Lin, 2014). Diversified research methods have been adopted, such as ecological environment dynamic change monitoring and analysis with GIS and remote sensing monitoring technique, ecological environment sensitivity research based on fuzzy mathematical method, ecological environment vulnerability assessment with neural network method (Zhang et al., 2014; Belaqziz et al., 2013; Aloisio et al., 1997, 1999, 2005). 
Investigation and survey indicate that most researches on ecological assessment at home and abroad focus on areas at national, provincial or county (municipal) levels, and few on areas at lower levels (Karamchand, 2006; Tehraniana et al., 2006; Wen et al., 2015). This paper is intended to analyze the ecological sensitivity and ecological risk of Manas County in Xinjiang from the aspects of land cover type, vegetation coverage index, geographic and geomorphic data, meteorological data, and soil type, and plan the areas of county development suitability and put forward ecological planning suggestions for different areas on this basis (Xiang et al., 2008; He and Xing, 2012; Zhang et al., 2016).

In this paper, a novel regional ecological assessment technology is proposed using improved ELECTRE method. In the proposed method, concordance index, nonconcordance index, credibility index, consistent credibility, non-consistent credibility and net credibility are defined firstly, and the preference matrix, the relation of group individuals is also defined. Based on these definitions, it can be sorted for the quality of all alternatives according to the net credibility. Experimental results suggest that the proposed improved ELECTRE method is feasible and valid to the regional ecological assessment.

\section{Improved ELECTRE method}

In order to be specific and not lose the generality, $C_{j}(j=1,2, \cdots, m)$ are all supposed to be benefit attributes. $p_{j}, q_{j}$ and $v_{j}$ signify strictly superior to the threshold value, indifference threshold value and veto threshold value respectively between projects on $C_{j}$, For the first kind of threshold value, suppose that $p_{j}$ is less than the difference between values of project $a_{j}$ and project $a_{k}$ on $C_{j}$, then we consider that the relation between $a_{j}$ and $a_{k}$ is that the former strictly superior to the latter; for the second kind of threshold value, suppose that $q_{j}$ is more than the difference between values of project $a_{j}$ and project $a_{k}$ on $C_{j}$, then it can be considered that there is indifference relation between these two projects; for the last threshold value, suppose that $v_{j}$ is less than or equal to the difference between values of project $a_{j}$ and project $a_{k}$ on $C_{j}$ (the value of $a_{k}$ is more than $a_{j}$ ), then we can vote down that the overall level of $a_{j}$ is superior to $a_{k}$, This shows that $0 \leq q_{j} \leq p_{j} \leq v_{j}$,

The improvements of the proposed ELECTRE method can be summarized as follows. Three novel indexes, Concordance Index, Non-concordance Index and Credibility Index are defined. Based on these indexes, a new Preference Matrix is constructed. Also, the Consistent Credibility, Non-consistent Credibility and Net Credibility are established. At the final, one novel approach is proposed to the Relation of Group Individuals and Sort of Group Decision.

\section{Definition of three indexes}

(1) Concordance Index, which can be expressed as $c\left(a_{i}, a_{k}\right)$, This index refers to the supporting degree to thesis that 'the level of $a_{i}$ is higher than $a_{k}$ ', which can be defined as 


$$
c\left(a_{i}, a_{k}\right)=\frac{1}{w} \sum_{j=1}^{m} w_{j} c_{j}\left(a_{i}, a_{k}\right)
$$

where

$$
\begin{aligned}
& w=\sum_{j=1}^{m} w_{j} \\
& c_{j}\left(a_{i}, a_{k}\right)=\left\{\begin{array}{lll}
0 & \text { if } & y_{j}\left(a_{i}\right)+p_{j} \leq y_{j}\left(a_{k}\right) \\
1 & \text { if } & y_{j}\left(a_{i}\right)+q_{j} \geq y_{j}\left(a_{k}\right) \\
\frac{y_{j}\left(a_{i}\right)+p_{j}-y_{j}\left(a_{k}\right)}{p_{j}-q_{j}} & \text { other } &
\end{array}\right.
\end{aligned}
$$

This index refers to the degree that project $a_{i}$ is superior to project $a_{k}$ on $C_{j}$,

(2) Non-concordance Index, which refers to the denying degree to thesis that 'the level of $a_{i}$ is higher than $a_{k}$, which can be defined as

$$
d_{j}\left(a_{i}, a_{k}\right)=\left\{\begin{array}{lll}
0 & \text { if } & y_{j}\left(a_{i}\right)+p_{j} \geq y_{j}\left(a_{k}\right) \\
1 & \text { if } & y_{j}\left(a_{i}\right)+v_{j} \leq y_{j}\left(a_{k}\right) \\
\frac{y_{j}\left(a_{k}\right)-y_{j}\left(a_{i}\right)-p_{j}}{v_{j}-p_{j}} & \text { other }
\end{array}\right.
$$

(3) Credibility Index, which refers to the credibility of that 'the level of $a_{i}$ is higher than $a_{k}$, the value of which can be defined as

$$
s\left(a_{i}, a_{k}\right)= \begin{cases}c\left(a_{i}, a_{k}\right) & \text { if } \quad \forall C_{j}, d_{j}\left(a_{i}, a_{k}\right) \leq c\left(a_{i}, a_{k}\right) \\ c\left(a_{i}, a_{k}\right) \times \prod_{c_{j}} \frac{1-d_{j}\left(a_{i}, a_{k}\right)}{1-c\left(a_{i}, a_{k}\right)} & \text { if } \quad \forall C_{j}, d_{j}\left(a_{i}, a_{k}\right)>c\left(a_{i}, a_{k}\right)\end{cases}
$$

\section{Build the preference matrix}

Every decision maker has his own point of view to judge and different preferences, so that they often use different dimensions and standards to make decisions (Duan et al., 2018; You et al., 2018; Liu et al., 2017; McKane et al., 2017). After finishing the ranking of alternatives by using ELECTRE-III method, we cannot simply use the 
average method or Borda method to integrate single decision result as the overall result, which does not conform to actual situations. Therefore, we need to put forward a new method to make the group reflect different dimensions and standards during the sorting process. Here, credibility index and the rating placement of project have greater relation with these dimensions and standards. We need to consider the following two questions at the same time: the relative interval of project while assigning the credibility index as $s\left(a_{k}, a_{i}\right)$ and $s\left(a_{i}, a_{k}\right)$, the relative rating placement of project on $s\left(a_{i}, a_{k}\right)$.

(1) Supposing that $\Delta Q_{l}\left(a_{i}, a_{k}\right)$ refers to the relative placement of project on $\left(a_{i}, a_{k}\right)$ in the sort. $Q_{l}\left(a_{i}\right)$ refers to the order made by person $l$ for project $a_{i}$. If there are $m$ projects to be ordered, person $l$ thinks that project $a_{i}$ is the best among all the projects, then the $Q_{l}\left(a_{i}\right)$ is defined as 1 . If person $l$ thinks that project $a_{i}$ is the worst one among all projects, then the $Q_{l}\left(a_{i}\right)$ is defined as $m$. There are five situations between the relative placement $\Delta Q^{l}\left(a_{i}, a_{k}\right)$ in ranking all projects and the project

$$
\Delta Q_{l}\left(a_{i}, a_{k}\right)=\left\{\begin{array}{lll}
Q_{l}\left(a_{i}\right)>>Q_{l}\left(a_{k}\right) & \text { if } & Q_{l}\left(a_{k}\right)-Q_{l}\left(a_{i}\right)>\frac{n}{2} \\
Q_{l}\left(a_{i}\right)>Q_{l}\left(a_{k}\right) & \text { if } & 0<Q_{l}\left(a_{k}\right)-Q_{l}\left(a_{i}\right) \leq \frac{n}{2} \\
Q_{l}\left(a_{i}\right)=Q_{l}\left(a_{k}\right) & \text { if } & Q_{l}\left(a_{k}\right)-Q_{l}\left(a_{i}\right)=0 \\
Q_{l}\left(a_{i}\right)<Q_{l}\left(a_{k}\right) & \text { if } & 0<Q_{l}\left(a_{i}\right)-Q_{l}\left(a_{k}\right) \leq \frac{n}{2} \\
Q_{l}\left(a_{i}\right)<<Q_{l}\left(a_{k}\right) & \text { if } & Q_{l}\left(a_{i}\right)-Q_{l}\left(a_{k}\right)>\frac{n}{2}
\end{array}\right.
$$

where $Q_{l}\left(a_{i}\right) \gg>Q_{l}\left(a_{k}\right)$ refers that person $l$ thinks project $a_{i}$ is much better than project $a_{k}, Q_{l}\left(a_{i}\right)>Q_{l}\left(a_{k}\right)$ refers that person $l$ thinks project $a_{i}$ is a little better than project $a_{k}, Q_{l}\left(a_{i}\right)<Q_{l}\left(a_{k}\right)$ refers that person $l$ thinks project $a_{i}$ is a little worse than project $a_{k}, Q_{l}\left(a_{i}\right)<<Q_{l}\left(a_{k}\right)$ refers that person $l$ thinks project $a_{i}$ is much worse than project $a_{k}$,

When it is necessary to determine the quality sequence of projects, traditional ELECTRE method usually consider that there exists outranking relation while $s\left(a_{i}, a_{k}\right) \geq \lambda_{\max }-\beta$ is found, $\lambda_{\max }=\max _{a_{i}, a_{k} \in A} s\left(a_{i}, a_{k}\right), \beta$ is the intercepting threshold, the value of which is setting by decision makers themselves according to their own experience. Among all these outranking relations, the quality sequence of project $a_{i}$ can be determined according to the difference between the number of outflowing directed arc of project $a_{i}$ and the number of inflowing directed arc of project $a_{i}$. Therefore, there are four situations existed while defining the relative interval of credibility index $s_{l}\left(a_{i}, a_{k}\right)$ and $s_{l}\left(a_{k}, a_{i}\right)$ among each pair-projects

Zone I: $s_{l}\left(a_{i}, a_{k}\right) \geq \lambda_{\max }-\beta, s_{l}\left(a_{k}, a_{i}\right) \geq \lambda_{\max }-\beta$ 
Zone II: $s_{l}\left(a_{i}, a_{k}\right) \geq \lambda_{\max }-\beta, s_{l}\left(a_{k}, a_{i}\right)<\lambda_{\max }-\beta$

Zone III: $s_{l}\left(a_{i}, a_{k}\right)<\lambda_{\max }-\beta, s_{l}\left(a_{k}, a_{i}\right) \geq \lambda_{\max }-\beta$

Zone IV: $s_{l}\left(a_{i}, a_{k}\right)<\lambda_{\max }-\beta, s_{l}\left(a_{k}, a_{i}\right)<\lambda_{\max }-\beta$

(2) Build the Preference Evaluation Matrix (Table 1). Preference Evaluation Matrix is used to measure the quality between project $a_{i}$ and project $a_{k}$.

Table 1. Preference evaluation matrix

\begin{tabular}{c|c|c|c|c}
\hline & Zone I & Zone II & Zone III & Zone IV \\
\hline$Q_{l}\left(a_{i}\right)>>Q_{l}\left(a_{k}\right)$ & $a_{i} O_{s} a_{k}$ & $a_{i} O_{s} a_{k}$ & $a_{i} O_{w} a_{k}$ & $a_{i} O_{s} a_{k}$ \\
$Q_{l}\left(a_{i}\right)>Q_{l}\left(a_{k}\right)$ & $a_{i} O_{w} a_{k}$ & $a_{i} O_{s} a_{k}$ & $a_{i} I a_{k}$ & $a_{i} O_{w} a_{k}$ \\
$Q_{l}\left(a_{i}\right)=Q_{l}\left(a_{k}\right)$ & $a_{i} I a_{k}$ & $a_{i} O_{w} a_{k}$ & $a_{i} B_{w} a_{k}$ & $a_{i} I a_{k}$ \\
$Q_{l}\left(a_{i}\right)<Q_{l}\left(a_{k}\right)$ & $a_{i} B_{w} a_{k}$ & $a_{i} I a_{k}$ & $a_{i} B_{s} a_{k}$ & $a_{i} B_{w} a_{k}$ \\
$Q_{l}\left(a_{i}\right)<<Q_{l}\left(a_{k}\right)$ & $a_{i} B_{s} a_{k}$ & $a_{i} B_{w} a_{k}$ & $a_{i} B_{s} a_{k}$ & $a_{i} B_{s} a_{k}$ \\
\hline
\end{tabular}

$a_{i} O_{s} a_{k}$ refers that project $a_{i}$ is much better $\left(O_{s}\right)$ than project $a_{k} ; a_{i} O_{w} a_{k}$ refers that project $a_{i}$ is little better $\left(O_{w}\right)$ than project $a_{k} ; a_{i} I a_{k}$ refers that there is no difference $(I)$ between project $a_{i}$ and project $a_{k} ; a_{i} B_{w} a_{k}$ refers that project $a_{i}$ is little worse $\left(B_{w}\right)$ than project $a_{k} ; a_{i} B_{s} a_{k}$ refers that project $a_{i}$ is much worse $\left(B_{s}\right)$ than project $a_{k}$

\section{Consistent credibility, non-consistent credibility and net credibility}

(1) Consistent credibility $\Phi^{+}\left(a_{i}\right)$ indicates the degree that project $a_{i}$ superior to other projects, which can be defined as

$$
\Phi^{+}\left(a_{i}\right)=\sum_{a_{k} \in A} s\left(a_{i}, a_{k}\right), \forall a_{k} \in A
$$

(2) Non-consistent credibility $\Phi^{-}\left(a_{i}\right)$ is used to show the degree that other projects superior to project $a_{i}$, which can be defined as

$$
\Phi^{-}\left(a_{i}\right)=\sum_{a_{k} \in A} s\left(a_{k}, a_{i}\right), \forall a_{k} \in A
$$

(3) Net credibility $\Phi\left(a_{i}\right)$ can express the difference between consistent credibility and non-consistent credibility, which can be defined as

$$
\Phi\left(a_{i}\right)=\Phi^{+}\left(a_{i}\right)-\Phi^{-}\left(a_{i}\right)
$$


It can be sorted of the quality for all alternatives according to the value of net credibility $\Phi\left(a_{i}\right)$. The greater the value of the net credibility $\Phi\left(a_{i}\right)$ of a project, the better the project is.

\section{Relation of group individuals}

(1) Group concordance index $C_{G}\left(a_{i}, a_{k}\right)$ refers to the credibility of supporting thesis that 'project $a_{i}$ is better than project $a_{k}$ ' from the perspective of group, which can be defined as

$$
C_{G}\left(a_{i}, a_{k}\right)=\sum_{l=1}^{m} v_{l} f_{l}\left(a_{i}, a_{k}\right)
$$

where

$$
f_{l}\left(a_{i}, a_{k}\right)=\left\{\begin{array}{lll}
1 & \text { if } & a_{i} O_{s} a_{k} \\
0.75 & \text { if } & a_{i} O_{w} a_{k} \\
0.5 & \text { if } & a_{i} I a_{k} \\
0.25 & \text { if } & a_{i} B_{w} a_{k} \\
0 & \text { if } & a_{i} B_{s} a_{k}
\end{array}\right.
$$

(2) Group non-concordance index $D_{G}\left(a_{i}, a_{k}\right)$ refers to the credibility of denying thesis 'project $a_{i}$ is better than project $a_{k}$ ' from the perspective of group, which can be defined as

$$
D_{G}\left(a_{i}, a_{k}\right)=\sum_{l=1}^{m} v_{l} g_{l}\left(a_{i}, a_{k}\right)
$$

where

$$
g_{l}\left(a_{i}, a_{k}\right)=\left\{\begin{array}{ll}
1 & \text { if } \quad \\
0 & \text { other }
\end{array} \quad\left(a_{i} B_{w} a_{k} \text { or } a_{i} B_{s} a_{k}\right) \&\left(Q_{l}\left(a_{i}\right)<<Q_{l}\left(a_{k}\right)\right)\right.
$$

(3) Group credibility index $S_{G}\left(a_{i}, a_{k}\right)$ refers to the credibility of thesis that 'project $a_{i}$ is better than project $a_{k}$ ', which can be defined as

$$
S_{G}\left(a_{i}, a_{k}\right)=C_{G}\left(a_{i}, a_{k}\right) \cdot\left(1-D_{G}\left(a_{i}, a_{k}\right)\right)
$$

\section{Sort of group decision}

(1) Group consistency credibility $\Phi_{G}^{+}\left(a_{i}\right)$ refers to estimate the credibility that project $a_{i}$ is better than other projects from the perspective of group, which can be defined as 


$$
\Phi_{G}^{+}\left(a_{i}\right)=\sum_{k=1}^{n} S_{G}\left(a_{i}, a_{k}\right)
$$

(2) Group non-consistency credibility $\Phi_{G}^{-}\left(a_{i}\right)$ refers to estimate the credibility that other projects are better than project $a_{i}$ from the perspective of group, which can be defined as

$$
\Phi_{G}^{-}\left(a_{i}\right)=\sum_{k=1}^{n} S_{G}\left(a_{k}, a_{i}\right)
$$

(3) Group net credibility $\Phi_{G}\left(a_{i}\right)$ refers to the difference between $\Phi_{G}^{+}\left(a_{i}\right)$ and $\Phi_{G}^{-}\left(a_{i}\right)$, which can be defined as

$$
\Phi_{G}\left(a_{i}\right)=\Phi_{G}^{+}\left(a_{i}\right)-\Phi_{G}^{-}\left(a_{i}\right)
$$

It can be sorted for the quality of all alternatives according to the value of $\Phi_{G}\left(a_{i}\right)$. In general, the greater the value of the group net credibility of a project, the better the project is.

\section{Experimental results}

In the experimental section, we take the Manas County (see Fig. l) as the research object, which located at Xinjiang autonomous region, P. R. China. Manas County is located in the middle section of North Slope of the Tian-Shan Mountains, bordered by Hu-Tu-Bi County in the east, Shi-He-Zi and Sha-Wan city in the west, He-Jing County in the south, and Hoboksar Mongol Autonomous County in the north. In respect of geographical coordinates, it stretches from $43^{\circ} 28^{\prime} 29^{\prime \prime}$ to $45^{\circ} 38^{\prime} 52^{\prime \prime}$ north latitude and from $85^{\circ} 41^{\prime} 16^{\prime \prime}$ to $86^{\circ} 43^{\prime} 10^{\prime \prime}$ east longitude. Manas County takes the shape of strip long from north to south and narrow from west to east. It is $235 \mathrm{~km}$ long to the most and $118 \mathrm{~km}$ wide to the most. The whole county covers an area of $10.196 .4 \mathrm{~km}^{2}$, and has seven towns, four villages, two farms and one station, as well as Xin-Hu Farm of the Sixth Agricultural Division of Xin-Jiang Production and Construction Corps, and four regimental farms of the Eighth Agricultural Division, namely 147 regiment, 148 regiment, 149 regiment and 150 regiment. Geomorphically, Manas County can be divided into three units from south to north, namely southern mountain area, central plan, and northern desert, of which the altitude ranges from $5,222 \mathrm{~m}$ to $650 \mathrm{~m}$, from $650 \mathrm{~m}$ to $320 \mathrm{~m}$ and from $320 \mathrm{~m}$ to $280 \mathrm{~m}$ respectively. Manas County falls into the dry and semi-dry temperate continental climate region, of which the climate features are severe cold winter, hot summer, abundant sunshine, aridness, and little rainfall, with annual average temperature of $6.9^{\circ} \mathrm{C}$ and average annual precipitation of $173.3 \mathrm{~mm}$.

\section{Basic data}

The main data used in this research covers land cover type, Normalized Differential Vegetation Index (NDVI), geographic and geomorphic data, meteorological data, soil 
type, distribution data of geological disaster, and administrative map. Table 2 shows the data sources and details.

Table 2. Data contents and sources

\begin{tabular}{c|c|c}
\hline Data name & Data source & Description \\
\hline Land cover type & $\begin{array}{c}\text { Institute of Geographic Sciences and } \\
\text { Natural Resources Research, CAS }\end{array}$ & Vector data of year 2017 \\
\hline $\begin{array}{c}\text { Environmental and Ecological Science } \\
\text { Data Center for West China, National } \\
\text { Natural Science Foundation of China }\end{array}$ & $\begin{array}{c}\text { SPOT VGT NDVI 1 km resolution } \\
\text { data of year 2009-2017 }\end{array}$ \\
\hline Digital elevation data & NASA SRTM3 data & 90 m resolution grid data of year 2017 \\
\hline Geomorphic data & $\begin{array}{c}\text { Land and Resource Department of } \\
\text { Manas County }\end{array}$ & Geomorphic unit zoning of year 2017 \\
\hline Soil type data & Manas County Bureau of Agriculture & $\begin{array}{c}\text { Data of rainfall, snow and } \\
\text { Soil distribution and type of year 2017 }\end{array}$ \\
\hline $\begin{array}{c}\text { Distribution of } \\
\text { geological disaster }\end{array}$ & $\begin{array}{c}\text { Land and Resource Department of } \\
\text { Manas County }\end{array}$ & $\begin{array}{c}\text { Distribution of places prone to and } \\
\text { classifications of geological disasters } \\
\text { of year 2017 }\end{array}$ \\
\hline $\begin{array}{c}\text { Administrative } \\
\text { division }\end{array}$ & $\begin{array}{c}\text { Land and Resource Department of } \\
\text { Manas County }\end{array}$ & $\begin{array}{c}\text { Vector boundary diagram of Manas } \\
\text { County and villages and towns of year } \\
\text { 2017 }\end{array}$ \\
\hline
\end{tabular}

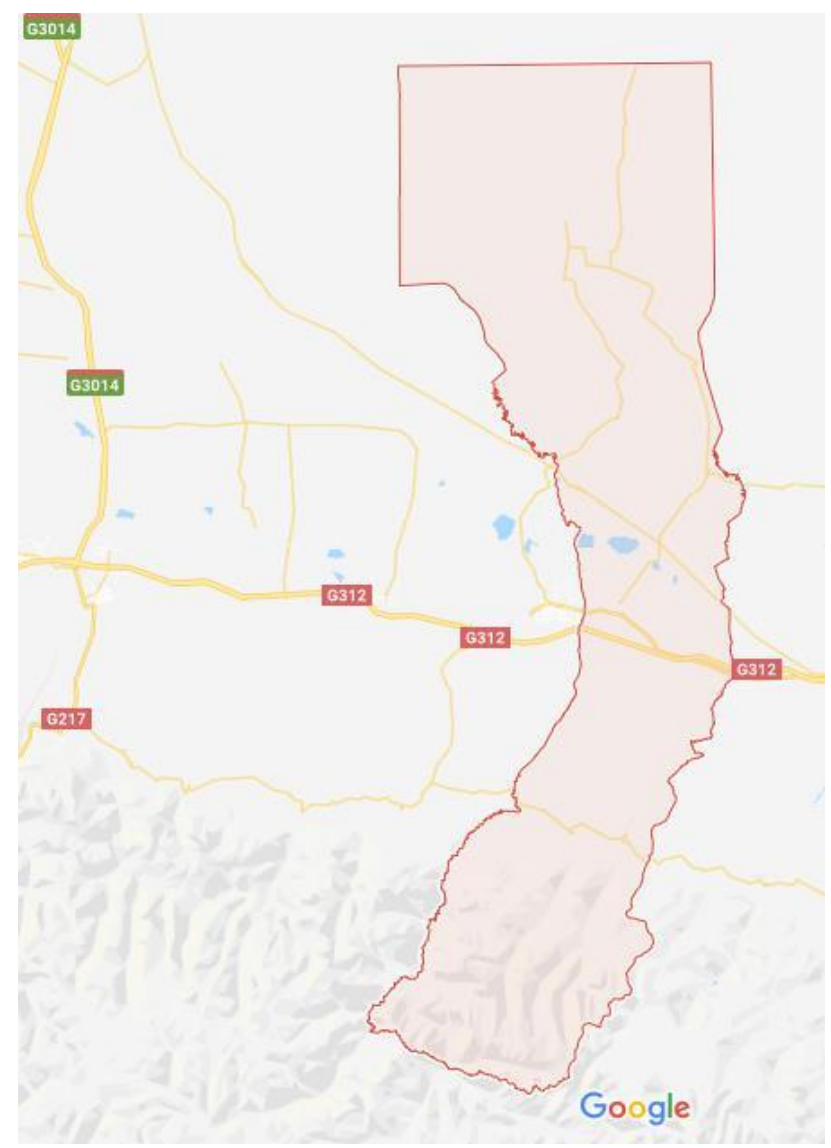

Figure 1. The location of Manas County 
Considering that the data is from different sources, it is necessary to preprocess the data before ecological analysis, including correction of remote sensing image data, scanning vectorization and registration of grid data, mergence and clipping of grid data based on administrative boundary map of county region. Essential data on the survey region has been generated with $\mathrm{Xi}$-An trimetric projection zone coordinate system based on the preprocessed data.

\section{Ecological sensitivity analysis}

The term of ecological sensitivity analysis in this research refers to the level of sensitivity of inhabiting area of major species in an ecosystem to interference of human activity, or the adaptive capacity of inhabiting area of major species in an ecosystem to external disturbance, which, with respect to selection of ecological factor, complies with the principles of representativeness, reliability, combination of qualitative analysis and quantitative analysis, and data availability (Sheikhhosseini, 2018; Fang et al., 2018; Dong et al., 2018). For constructing the indicator system, comprehensive consideration of natural factors and anthropogenic influence has been taken, and the selected sensitivity assessment indicators including land cover factor, vegetation factor, slope, geomorphic type, and groundwater protection zone factor. For land cover factor, landuse type is taken as the assessment indicator, and national forest parks and major wetlands are taken into full consideration; for vegetation factor, NDVI is taken as the assessment indicator; for geomorphic factor, geomorphic division type is taken as the assessment indicator (Zhang et al., 2017; Obraczka et al., 2017).

In this research, the attributes of the assessment indicators are assessed, and a value ranging from 1 to 9 is assigned to each indicator. High value indicates high level of ecological sensitivity (as shown in Table 3, ' $\%$ indicates that it would contain nonrelevant information). A weight is assigned to land cover factor, NDVI, slope, geomorphology, and underground water factor respectively, which is $0.4,0.1,0.2,0.2$ and 0.1 respectively. A $30 \mathrm{~m} \times 30 \mathrm{~m}$ grid cell is taken as analytical unit, and the weighted sum of the factors is calculated with grid calculator in ArcGIS 9.3. Based on the calculations, the ecologically sensitive region is divided into five levels with 5-level division method, namely high sensitive area, relatively highly sensitive area, medium sensitive area, low sensitive area and non-sensitive area.

Table 3. Manas County ecosystem sensitivity assessment indicator

\begin{tabular}{c|c|c|c|c|c|c|c|c|c}
\hline Item & $\mathbf{1}$ & $\mathbf{2}$ & $\mathbf{3}$ & $\mathbf{4}$ & $\mathbf{5}$ & $\mathbf{6}$ & $\mathbf{7}$ & $\mathbf{8}$ & $\mathbf{9}$ \\
\hline Land cover & Urban & $/$ & $/$ & Farmland & $/$ & Deseed & Grassland & Other & $\begin{array}{c}\text { Forest, } \\
\text { wetland }\end{array}$ \\
\hline NDVI & $\leq 0$ & $/$ & $(0,0.25]$ & $/$ & $\begin{array}{c}(0.25- \\
0.5]\end{array}$ & $/$ & $\begin{array}{c}(0.50- \\
0.75]\end{array}$ & $/$ & $(0.75-1]$ \\
\hline Slope & $\leq 5^{\circ}$ & $/$ & $\left(5^{\circ}-15^{\circ}\right]$ & $/$ & $\left(15^{\circ}-25^{\circ}\right]$ & $/$ & $>25^{\circ}$ & $/$ & $/$ \\
\hline $\begin{array}{c}\text { Geomorphology } \\
\text { Underground } \\
\text { water }\end{array}$ & $\begin{array}{c}\text { Non- } \\
\text { protective } \\
\text { zone }\end{array}$ & $\begin{array}{c}\text { Fine } \\
\text { soil } \\
\text { plain }\end{array}$ & $\begin{array}{c}\text { Inclined } \\
\text { plain }\end{array}$ & Desert & $/$ & Hill & $\begin{array}{c}\text { Middle } \\
\text { mountain }\end{array}$ & $/$ & $\begin{array}{c}\text { High } \\
\text { mountain }\end{array}$ \\
\hline
\end{tabular}




\section{Ecological risk analysis}

For purpose of this research, comprehensive ecological risk assessment method is adopted. According to field research and materials and documents, the three major ecological risks in Manas County include flood, desert, and geological disaster. An ecological risk assessment model has been built based on the results of risk exposure in combination with the intensity and frequency of risk. For the analysis, the collected research data is digitized first, and then further collated, verified and edited. On this basis, a database is built on the ArcGIS platform, and calculation and analysis are made according to the needs of assessment.

The flood types in Manas County mainly include snow (ice)-melted flood, rainstormtype flood and blended-type flood. In the research, analysis is made on runoff of snow, rainstorm and small watershed, the probability of occurrence of flood is determined according to different catchment areas, and a certain area on both sides of river reach prone to flood is taken as the risky place. In the research on desertization risk, vegetation index, soil type, and average annual precipitation are taken as the assessment factors of desertization risk grade, and desertization risk classification is made. In the research on risk of landslide and debris flow, a geological disaster ecological risk formula of Manas County is established with slope, rainstorm and vegetation coverage as the assessment factors. At last, on the basis of main ecological risk analysis, the three risks set out above are normalized and graded respectively (as shown in Table 4), a weight of $0.40,0.35$ and 0.25 is assigned to flood risk, desertization risk and geologic risk respectively, and weighting calculation is conducted. Limited to human recognition, $1,3,5,7,9$ are often used to distinguish the difference between two objects. Based on the results, the ecological risk area is divided into high risk area, relatively high risk area, moderate risk area, relatively low risk area and low area with the 5-level division method.

Table 4. Manas County ecological risk assessment indicators

\begin{tabular}{c|c|c|c|c|c}
\hline Degree of risk & $\mathbf{1}$ & $\mathbf{3}$ & $\mathbf{5}$ & $\mathbf{7}$ & $\mathbf{9}$ \\
\hline Flood risk & $(0.04,0.08]$ & $(0.08,0.17]$ & $(0.17,0.33]$ & $(0.33,0.58]$ & $(0.58-1]$ \\
Desertization risk & $(0.44,0.53]$ & $(0534,0.60]$ & $(0.60,0.65]$ & $(0.65,0.70]$ & $(0.70,0.85]$ \\
Geological risk & $(0.11,0.25]$ & $(0.25,0.34]$ & $(0.34,0.45]$ & $(0.45,0.56]$ & $(0.56,0.80]$ \\
\hline
\end{tabular}

\section{Suitability analysis of county development}

According to the normalization with equal weight of the results of ecological sensitivity analysis and ecological risk analysis of Manas County and suitability analysis of county development, the highly ecologically sensitive area and highly ecological risk area are unsuitable for county development, relatively high ecologically sensitive area and relatively high risk area are barely suitable for county development, medium ecologically sensitive area and medium ecological risk area are moderately suitable for county development, and low ecologically sensitive area and low ecological risk area are highly suitable for county development. The ecology, safety, resources, environment and urban functions of areas unsuitable and barely suitable for county development are vulnerable, which are difficult to restore or will lead to heavy losses once being damaged. Proper control measures should be taken in areas moderately 
suitable for county development according to the requirements of ecology, safety, resources and environment. Concentrated construction is feasible in areas highly or relatively highly suitable for county development.

\section{Results of comprehensive ecological sensitivity analysis}

According to the ecosystem sensitivity assessment indicators of Manas County, the highly sensitive area in the whole Manas County mainly covers the water conservation area in the south, wetlands in the central part, and desert in the north, and other areas most are moderately sensitive areas. The proportions of highly sensitive area, relatively highly sensitive area, moderately sensitive area, low sensitive area, and non-sensitive area to the total area of the survey region are $41.31 \%, 16.17 \%, 16.44 \%, 7.07 \%$ and $19.01 \%$ respectively.

\section{Results of comprehensive ecological risk analysis}

According to the ecological risk assessment system, the high-ecological-risk area of Manas County is mainly distributed in the south of Taxihe Village, the middle part and south of Qing-Shui-He Village, and the north of Guang-Dong-Di Village. The ecological risk level of the area along the downstream of Taxihe and the area along the downstream of Manas River is also relatively high, and that of other areas is low.

\section{Results of suitability analysis of Manas County development}

The suitability analysis results of county development are classified into five grades. The area highly suitable for county development mainly covers most areas of Manas town, Lan-Hou-Wan town, the west area of 147 regimental farm, Bei-Wu-Cha, the southeast of Liu-Hu-Di, as well as the east of 148 regimental farm, 149 regimental farm and 150 regimental farm; the area relatively highly suitable for county development mainly covers the middle part of the four regimental farms, the south of Lan-Zhou-Wan, Le-Tu-Yi and the south of Bao-Jia-Dian; the area moderately suitable for county development mainly covers Xin-Hu Farm and most area of Guang-Dong-Di village; the rest area is barely suitable or unsuitable for county development, mainly covering the northern desert, southern mountain, the area along Manas River and Taxihe, and reservoirs and swags in plain area.

\section{Manas County construction regionalization}

Manas County is regionalized according to the suitability analysis of Manas County development, by which the areas barely suitable or unsuitable for county development are classified into prohibited-construction areas, and the areas relatively highly or highly suitable for county development into construction-suitable areas. The prohibitedconstruction areas mainly cover the southern mountains, wetlands in the plain area, and the northern desert. The north slope of the Tian-Shan Mountains is highly sensitive water conservation area; most primeval forest and vegetation have been damaged in the process of bringing wasteland into cultivation; the area of the north desert has been put under proper control with the expansion of cultivated land and the construction of wind break, but it is still an ecologically sensitive area needing intensive protection. These areas set out above should be prohibited for development in urban construction (Fig. 2). 


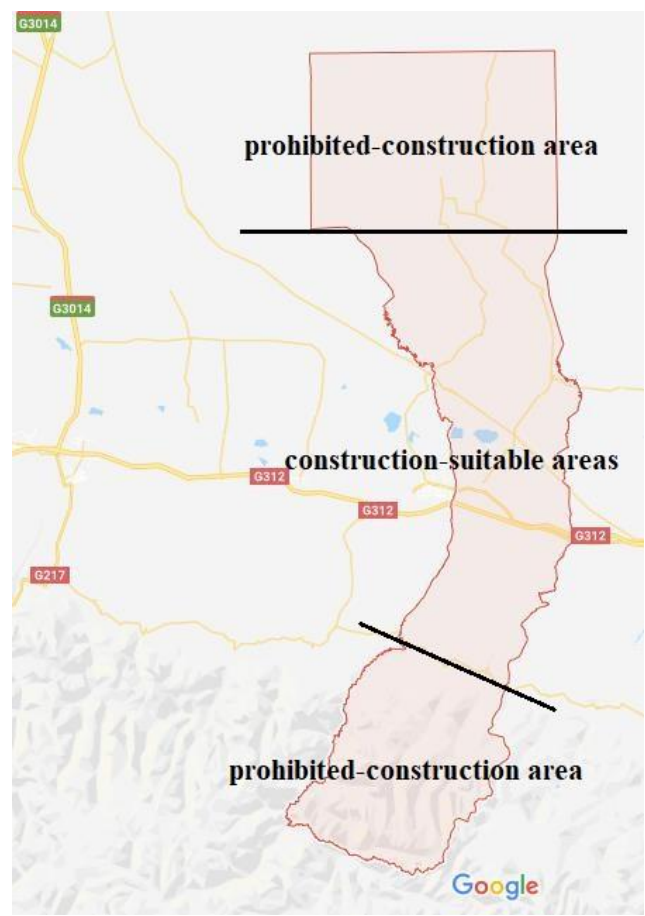

Figure 2. The prohibited-construction area and construction-suitable area of Manas County

\section{Conclusions}

In this paper, relatively comprehensive ecological assessment of Manas County has been made through ecological sensitivity analysis and ecological risk analysis by combining expert knowledge with the analytic hierarchy process and bringing the spatial analysis capability of GIS into full play, providing new ideas for ecological quality assessment and urban development planning. In the scope of Manas County, the highly sensitive area is mainly distributed in the water conservation area in the south mountains, wetlands in the central part, and desert in the north; the proportions of highly sensitive area, relatively highly sensitive area, moderately sensitive area, low sensitive area, and non-sensitive area to the total area of the survey region are $41.31 \%$, $16.17 \%, 16.44 \%, 7.07 \%$ and $19.01 \%$ respectively; the highly ecological risk area is mainly distributed in the south of Taxihe Village, the middle part and south of QingShui-He Village, and the north of Guang-Dong-Di Village, as well as the middle and lower reaches of Taxihe and the lower reaches of Manas River. According to ecological sensitivity analysis and ecological risk analysis, county development suitability analysis has been made in this research, and the survey region is classified into prohibitedconstruction area, construction expansion restricted zone, and construction-suitable area on this basis. The construction of any unrelated building should be prohibited in the prohibited-construction area, measures should be taken to avoid occupying urban construction land in the constructive expansion restricted zone as far as possible, and rational development on the premise of ecological environmental protection is allowed in the construction-suitable area.

According to the ecological sensitivity analysis and ecological risk analysis, the middle and lower reaches of Manas River and the upper and middle reaches of Taxihe are flood-prone area, of which the comprehensive ecological safety assessment index takes on a down trend. A special fund allocated by the Ministry of Water Resources was 
used for flood control of Manas River in 2011. The feasible measures for flood control include consolidating the construction of small and medium size reservoirs and infrastructure of flood control and drainage of cities, and mitigating damage to Manas River and Taxihe. For severe desertification region, it needs to strengthen the construction of vegetation, river, road, and other ecological corridors in the junction zone between desert and city, to prevent desertification erosion. For the highly sensitive and risk areas such as the high mountains and gorge areas in Manas County, ecological emigration from the steep slope area along Manas River and Taxihe can be considered to resettle the scattered residents in an area of low ecological risk centrally. For county development, the construction of unrelated buildings should be prohibited in the prohibited-construction area; measures should be taken to avoid occupying urban construction land in the constructive expansion restricted zone as far as possible, or proper ecological assessment, compensation measures and the procedure for examination and approval should be subject to if it needs to occupy any urban construction land in special circumstance; the principles of construction following planning, optimal land utilization, intensive development, and rational exploitation on the premise of ecological environmental protection should be adhered to for the construction-suitable area.

Acknowledgements. This study was supported by Key project of important topic of humanities and social sciences research of Hebei province (project number: ZD201719), and Fund of key research base of humanities and social sciences of institutions of higher learning of Hebei province (project number: JJJD1710).

\section{REFERENCES}

[1] Aloisio, G., Cafaro, M., Williams, R., et al. (1997): A distributed web-based metacomputing environment. - Proceedings of High-Performance Computing and Networking (Lecture Notes in Computer Science) 1225: 480-486.

[2] Aloisio, G., Cafaro, M., Fiore, S., et al. (2005): A grid-based architecture for earth observation data access. - ACM Symposium on Applied Computing, Santa Fe, New Mexico, USA, pp. 701-705.

[3] Aloisio, G., Cafaro, M., Williams, R. (1999): The digital Puglia project: an active digital library of remote sensing data. - Proceedings of the 7th International Conference on High Performance Computing and Networking Europe 1593: 563-572.

[4] Anbari, F. T. (2003): Earned value project management method and extensions. - Project Management Journal 12: 12-23.

[5] Belaqziz, S., Khabba, S., Er-Raki, S., et al. (2013): A new irrigation priority index based on remote sensing data for assessing the networks irrigation scheduling. - Agricultural Water Management 119: 1-9.

[6] Bi, W., Dandy, G. C., Maier, H. R. (2015): Improved genetic algorithm optimization of water distribution system design by incorporating domain knowledge. - Environmental Modelling and Software 69: 370-381.

[7] Changdar, C., Mahapatra, G. S., Pal, R. K. (2015): An improved genetic algorithm based approach to solve constrained knapsack problem in fuzzy environment. - Expert Systems with Applications 42(4): 2276-2286.

[8] Dong, Q., Yuan, J., Chen, X., Ma, X. (2018): Reduction of moisture susceptibility of cold asphalt mixture with Portland cement and bentonite nanoclay additives. - Journal of Cleaner Production 176: 320-328. 
[9] Duan, M., Liu, Z., Yan, D., Peng, W., Baghban, A. (2018): Application of LSSVM algorithm for estimating higher heating value of biomass based on ultimate analysis. Energy Sources Part A - Recovery Utilization and Environmental Effects 40(6): 709-715.

[10] Fang, L., Wang, X., Guo, L., Liu, Q. (2018): Antioxidant, anti-microbial properties and chemical composition of cumin essential oils extracted by three methods. - Open Chemistry 16(1): 291-297.

[11] He, R. J., Xing, L. N. (2012): A learnable ant colony optimization to the disasters monitoring task allocation problem. - Research Journal of Chemistry and Environment 16(S2): 18-26.

[12] Heilmann, R. (2003): Discrete optimization a branch-and-bound procedure for the multimode resource-constrained project scheduling problem with minimum and maximum time lags. - European Journal of Operational Research 144: 348-365.

[13] Karamchand, S. S. (2006): Operator Scheduling in a Distributed Stream Management System for Remotely Sensed Imagery. - University of California, Davis, USA.

[14] Lin, C. H., Lin, P. L. (2014): Improving the non-dominated sorting genetic algorithm using a gene-therapy method for multi-objective optimization. - Journal of Computational Science 5(2): 170-183.

[15] Liu, Y., Li, T., Guo, L., Zhang, R., Feng, X., Liu, K. (2017): The mediating role of sleep quality on the relationship between perceived stress and depression among the elderly in urban communities: a cross-sectional study. - Public Health 149: 21-27.

[16] McKane, A., Therkelsen, P., Scodel, A., Rao, P., Aghajanzadeh, A., Hirzel, S., Zhang, R., Prem, R., Fossa, A., Lazarevska, A. M., Matteini, M., Schreck, B., Allard, F., Alcantar, N. V., Steyn, K., Hurdogan, E., Bjorkman, T., O'Sullivan, J. (2017): Predicting the quantifiable impacts of iso 50001 on climate change mitigation. - Energy Policy 107: 278-288.

[17] Nichols, D. C., Wahlen, J. M. (2004): How do earnings numbers relate to stock returns, a review of classic accounting research with updated evidence. - Accounting Horizons 18(4): 263-286.

[18] Obraczka, M., Beyeler, M., Magrini, A., Legey, L. F. (2017): Analysis of coastal environmental management practices in subregions of California and Brazil. - Journal of Coastal Research 33(6): 1315-1332.

[19] Sheikhhosseini, E. (2018): Design and effective synthesis of novel furo[2,3-d]pyrimidine derivatives containing ethylene ether spacers. - Journal of Saudi Chemical Society 22(3): 337-342.

[20] Tehraniana, S., Zhao, Y. S., Harveya, T., et al. (2006): A robust framework for real-time distributed processing of satellite data. - Journal of Parallel Distributed Computing 66: 403-418.

[21] Wen, X. Z., Shao, L., Xue, Y., et al. (2015): A rapid learning algorithm for vehicle classification. - Information Sciences 295(1): 395-406.

[22] Xiang, B., Li, G. Q., Liu, D. S., et al. (2008): Research on task management and scheduling of high performance remote sensing satellite ground pre-processing system. Journal of Astronautics 29(4): 1443-1446.

[23] Yang, Y. S., Xu, B. W., Li, J. J. (2015): An improved genetic algorithm for fast configuration design of large-scale container cranes. - Journal of Information and Computational Science 12(11): 4319-4330.

[24] You, J., Sun, Y., Bo, Y., Zhu, Y., Duan, D., Cui, H., Lu, Q. (2018): The association between dietary isoflavones intake and gastric cancer risk: a meta-analysis of epidemiological studies. - BMC Public Health 18(510).

[25] Zhang, L., Sun, J., Guo, C. (2017): A novel multi-objective discrete particle swarm optimization with elitist perturbation for reconfiguration of ship power system. - Polish Maritime Research 24(SI): 79-85. 
[26] Zhang, W. F., Wang, L. Z., Ma, Y., et al. (2014): Design and implementation of task scheduling strategies for massive remote sensing data processing across multiple data centers. - Software-Practice and Experience 44(7): 873-886.

[27] Zhang, Y. H., Sun, X. M., Wang, B. W. (2016): Efficient algorithm for K-barrier coverage based on integer linear programming. - China Communications 13(7): 16-23.

[28] Zhao, Z. J. (2003): An analysis of the deviation of stock market price from its intrinsic value. - Economic Research Journal 10: 66-74.

[29] Zou, Y. Y., Zhang, Y. D., Li, Q. H., et al. (2015): Improved multi-objective genetic algorithm based on parallel hybrid evolutionary theory. - International Journal of Hybrid Information Technology 8(1): 133-140.

[30] Zuo, X. Q., Chen, C., Tan, W., et al. (2015): Vehicle scheduling of an urban bus line via an improved multi-objective genetic algorithm. - IEEE Transactions on Intelligent Transportation Systems 16(2): 1030-1041. 